\section{Differential Response of Weeds and Vegetable Crops to Aqueous Extracts of Hairy Vetch and Cowpea}

\author{
Erin C. Hill, Mathieu Ngouajio, ${ }^{1}$ and Muraleedharan G. Nair \\ Department of Horticulture, Michigan State University, A285 Plant and Soil \\ Science Bldg., East Lansing, MI 48824
}

Additional index words. allelopathy, Abutilon theophrasti, Allium cepa, Amaranthus
retroflexus, Asclepias syriaca, Capsicum annum, Cucumis sativus, Daucus carota,
Echinochloa crus-galli, Lactuca sativa, Lycopersicon esculentum, Stellaria media, Zea mays

Abstract. Laboratory experiments were conducted to study the effect of aqueous extracts of hairy vetch (Vicia villosa Roth) and cowpea (Vigna unguiculata (L.) Walp) cover crops on germination and radicle elongation in seven vegetable and six weed species. Lyophilized aqueous extracts of the cover crops were dissolved in reverse osmosis (RO) water to produce seven concentrations: $0.00,0.25,0.50,1.00,2.00,4.00$, and $8.00 \mathrm{~g} \cdot \mathrm{L}^{-1}$. Each treatment had 4 replications and the full experiment was repeated. Experiment 1 (E1) and Experiment (E2) were conducted under similar conditions. In general, seed germination was not affected by extracts of both cover crops. However, radicle growth of all species tested (except common milkweed exposed to cowpea extract) was affected by the cover crop residue extracts. Low concentrations of hairy vetch extract stimulated the radicle growth of carrot, pepper, barnyardgrass, common milkweed, and velvetleaf. Likewise, low concentrations of cowpea extract stimulated the growth of corn, barnyardgrass, and velvetleaf. At higher concentrations all species tested were negatively affected. The order of species sensitivity to the hairy vetch extract, as determined by the $\mathrm{IC}_{50}$ (concentration required to produce $50 \%$ radicle inhibition) values, was common chickweed $>$ redroot pigweed $>$ barnyardgrass $\mathrm{E} 1>$ carrot $\mathrm{E} 1>$ wild carrot $>$ corn $>$ carrot $\mathrm{E} 2>$ lettuce $>$ common milkweed $>$ tomato $>$ onion $>$ barnyardgrass E2 $>$ velvetleaf $>$ pepper $>$ cucumber (most sensitive to least sensitive). For cowpea the order was common chickweed $>$ redroot pigweed $>$ corn $>$ tomato $>$ lettuce $>$ wild carrot $>$ pepper $>$ carrot $>$ cucumber $>$ onion $>$ barnyardgrass and velvetleaf. Results suggest that the susceptibility of weeds and vegetable crops to aqueous extracts of hairy vetch and cowpea is dependent on both species and extract concentration.

Cover crops are integrated into vegetable cropping systems for their many favorable traits, including nutrient acquisition, erosion control, and weed suppression. However, in some cases the cover crop residue has been a detriment to the cash crop, reducing establishment, growth, and yield (Putnam, 1986; Teasdale, 1996). Allelopathy is one of the proposed causes of these effects. Allelopathy, a term coined by Hans Molisch (1937), is defined as interactions between plants that are biochemically facilitated by secondary compounds above and below ground. Allelopathy usually refers to negative interactions among plants. The microbial breakdown of secondary plant compounds can also result in chemicals with allelopathic properties (Chase et al., 1991; Weston and Duke, 2003). If released by the

Received for publication 1 Nov. 2005. Accepted for publication 5 Feb. 2006. Funding for this project was provided in part by USDA NCR-SARE grant No. 25-6205-0042-027, PPRC MSU (Pickle and Pepper Research Committee for Michigan State University), PPI (Pickle Packers International Inc.), and the Michigan Vegetable Council. Pickling cucumber seeds were provided by Seminis Inc. Weeds seeds were contributed by Ruth Mangum and Karen Renner. We would like to thank Juan Pedro Steibel for his assistance in the statistical analysis of this work.

${ }^{1}$ Corresponding author; e-mail ngouajio@msu.edu. plant into the environment, allelochemicals have the potential to affect neighboring plant life to varying degrees based on the quantity and persistence of the compound (Putnam, 1988). These two factors vary by species, chemical composition, and environmental conditions. Allelochemicals have been studied for their potential as natural herbicides, which could be safer for the environment than synthetics (Bhowmik and Inderjit, 2003).

The use of allelopathic legume cover crops is of particular interest because of their nitrogen fixing capabilities. Chung and Miller (1995) showed that aqueous extracts of alfalfa (Medicago sativa) can reduce weed germination by up to $60 \%$, depending on weed species and temperature. Hairy vetch (Vicia villosa) and cowpea (Vigna unguiculata) are legume cover crops that have been seen to reduce weed populations and to negatively affect some vegetable crops (Ngouajio and Mennan, 2005; Teasdale, 1996; White et al., 1989). Hairy vetch, a winter hardy species is primarily used in temperate regions, while cowpea, a warm season species, is used in tropical regions.

In 1989, White et al. found that hairy vetch aqueous extracts at 16.7 and $33.3 \mathrm{~g} \cdot \mathrm{L}^{-1}$ reduced corn and cotton (Gossypium hirsutum) germinations by $18 \%$ to $44 \%$ and $36 \%$ to $42 \%$, respectively. Corn and cotton seeds receiving $33.3 \mathrm{~g} \cdot \mathrm{L}^{-1}$ aqueous hairy vetch ex- tract showed 39 and $62 \%$ reduction in radicle length, respectively. In the same study, they found that the germination and radicle growth of pitted morningglory, wild mustard, and Italian ryegrass were inhibited in the presence of hairy vetch extract. In a 2-year field study, Hoffman et al. (1993) showed that live and chopped hairy vetch cover crops reduced weed emergence and thus density. However, all hairy vetch treatments, live, rolled, chopped, or killed with glyphosate, reduced corn yield to varying degrees compared to the bare ground, weed-free control. Recently, Ngouajio and Mennan (2005) reported reduced marketable cucumber yields in the presence of hairy vetch residues compared to a bare ground control during the second year of their 2-year study. During both years yields in hairy vetch plots were significantly lower than those in the sorghum sudangrass plots (Sorghum bicolor $\times$ S. sudanense) and rye (Secale cereale) plots. In the same study hairy vetch was shown to reduce weed density and biomass by up to 99 and $91 \%$, respectively, compared to the bare ground control.

Growth inhibition after a hairy vetch cover crop has been shown to be exacerbated under drought conditions (Hoffman et al., 1993; Ngouajio and Mennan, 2005). It is therefore possible that the responsible allelochemicals are water soluble, resulting in higher concentrations under conditions, such as drought, that reduce leaching. Germination and growth of several species was affected by aqueous extracts or hairy vetch (Teasdale and Pillai, 2005; White et al., 1989). In a recent study, Kamo et al. (2003) showed that cyanamide was a possible allelochemical from hairy vetch.

Cowpea has been linked to increased transplant death of broccoli (Brassica oleracea) (Schroeder et al., 1998). Phytotoxicity to 'Purple top' turnip (Brassica rapa) observed following a cowpea cover crop was attributed to allelopathy (Wang etal., 2003). Also, cowpea grown as a summer cover crop in pepper and lettuce production has been shown to reduce the density of weeds (Hutchinson and McGiffen, 2000; Ngouajio et al., 2003).

The studies mentioned above strongly suggest that hairy vetch and cowpea cover crops may be able to reduce weed density via allelochemicals, however, there is the risk of negative effects on subsequent vegetable crops. Plant sensitivity to hairy vetch was shown to vary with species and extract concentration. Understanding the sensitivity of weed and vegetable crop species to hairy vetch and cowpea could help select appropriate cover crops and crop rotations that would improve weed management while reducing the risk of crop injury. Therefore, this work intends to examine the germination and radicle response of a wide range of vegetables and weeds to hairy vetch and cowpea aqueous extracts.

\section{Materials and Methods}

Plant material extraction. Hairy vetch was planted in the field at the Horticulture Teaching and Research Center on the campus of Michigan State University in East Lansing, on 3 Sept. 
Table 1. Hairy vetch and cowpea aqueous extracts used in the bioassay tests and their corresponding fresh biomass.

\begin{tabular}{lcc}
\hline \multirow{2}{*}{$\begin{array}{l}\text { Extract } \\
\text { rate }^{\mathrm{y}}\end{array}$} & \multicolumn{3}{c}{$\begin{array}{c}\text { Corresponding fresh biomass } \\
\left(\mathrm{g} \cdot \mathrm{L}^{-1}\right)\end{array}$} \\
\cline { 2 - 3 } 0.00 & Cowpea & Hairy vetch \\
0.25 & 0.0 & 0.0 \\
0.50 & 7.8 & 11.3 \\
1.00 & 15.6 & 22.6 \\
2.00 & 31.1 & 45.2 \\
4.00 & 62.3 & 90.4 \\
8.00 & 124.5 & 180.8 \\
\hline
\end{tabular}

${ }^{\mathrm{z}}$ Equivalent fresh biomass extracted for one $\mathrm{L}$ of extract. Values were calculated using the ratio of 22.13 and $32.12 \mathrm{~g}$ of dry extract per $\mathrm{kg}$ of fresh biomass for hairy vetch and cowpea, respectively.

${ }^{y}$ Aqueous extracts were lyophilized to obtain a dry powder that was stored at $-40^{\circ} \mathrm{C}$. The powder was subsequently dissolved in $\mathrm{RO}$ water to obtain the required rate.

2003 and whole plants were harvested on 12 May 2004. Cowpea was planted on 17 June 2004 and whole plants were harvested on 27 Aug., 10 Sept., and 28 Sept., 2004. For each cover crop, the area harvested was recorded to allow for the calculation of the field rate of each extract. All plants were rinsed once with tap water and once with reverse osmosis (RO) water to remove soil. After rinsing, the plants were allowed to air dry before being weighed. The fresh plant material $(25.49 \mathrm{~kg}$ for hairy vetch and $31.15 \mathrm{~kg}$ for cowpea) were then chopped by hand and blended with 2.3 and 1.8 $\mathrm{L} \cdot \mathrm{kg}^{-1}$ of RO water for hairy vetch and cowpea, respectively, in an industrial blender (CB-10; Waring Commercial, Torrington, Conn.) for 30 to $60 \mathrm{sec}$. The pure blend was filtered through cheese cloth resulting in an average of 2.7 and $2.1 \mathrm{~L} \cdot \mathrm{kg}^{-1}$ for hairy vetch and cowpea, respectively. After centrifugation (RC5C; Sorvall Instruments, DuPont, Wilmington, Del.) at $10,000 \mathrm{rpm}$ for $10 \mathrm{~min}$, the resulting supernatants were the desired hairy vetch and cowpea aqueous extracts. Extracts were freeze dried using a tray-lyophilizer at $10^{\circ} \mathrm{C}$ and the resulting powders were mixed to allow for uniformity within each species. The powders were then stored at $-20^{\circ} \mathrm{C}$ until use. For the assays, the extracts for each cover crop were dissolved in $\mathrm{RO}$ water to afford concentrations of 0.00 , $0.25,0.50,1.00,2.00,4.00$, and $8.00 \mathrm{~g} \cdot \mathrm{L}^{-1}$ by serially diluting a stock solution containing $10 \mathrm{~g} \cdot \mathrm{L}^{-1}$. The corresponding cover crop fresh biomass is indicated in Table 1.
To estimate the concentration of the extract under field conditions, field equivalent concentrations were calculated based on the extract retrieved per unit of area harvested. These estimates were made using the assumptions of 1) $15 \mathrm{~cm}$ of cover crop incorporation which is the depth of incorporation of the cover crops by most growers, 2) simultaneous release of the extracted materials, and 3) $2.5 \mathrm{ml}$ of aqueous extract in each Petri dish, equating to $39.1 \mathrm{~L}$ per cubic meter of soil. The following equation was used to estimate field equivalent rates of the extracts:

$$
F E R=\frac{E(g)^{*} P\left(m^{3}\right)}{A\left(m^{2}\right)^{*} D(m)^{*} W(L)}
$$

where FER is the estimated extract field equivalent rate, $E$ is the total extract dry weight retrieved in g, $A$ is the cover crop area harvested, $P$ is the petri dish volume $\left(64 \mathrm{~cm}^{3}\right), D$ is the hypothetical depth of cover crop incorporation in the field $(15 \mathrm{~cm})$, and $W$ is the volume of extract solution added to the petri dish during the bioassay tests in L $(0.0025 \mathrm{~L})$. Because the extracted materials are likely released over time, and not simultaneously, these extractfield rate estimates are maximum rates.

Germination and radicle elongation assays. The vegetable crops examined were carrot, cucumber, lettuce, onion, pepper, sweet corn, and tomato, along with barnyardgrass, common chickweed, common milkweed, redroot pigweed, velvetleaf, and wild carrot weed species (Table 2). The experiment had a randomized complete block design comprised of seven extract concentration, thirteen species, and four replications with ten seeds each. The experiment was repeated once. For each species, the seeds were sterilized in a $1 \%$ sodium hypochlorite solution, rinsed three times with $\mathrm{RO}$ water, dried, and placed on a $90 \mathrm{~mm}$ Whatman No. 1 filter paper in a $100 \mathrm{~mm}$ plastic petri dish. The weed species required $24 \mathrm{~h}$ ( $48 \mathrm{~h}$ for velvetleaf) of soaking in $\mathrm{RO}$ water, after sterilization, to increase germination rates. Once placed on the filter paper, each dish received $2.5 \mathrm{~mL}$ of extract (sweet corn received $3.0 \mathrm{~mL}$, necessary for imbibition). After extract administration, the petri dishes were sealed using Parafilm and incubated in the dark for 4 to $11 \mathrm{~d}$ at the temperatures specified in Table 2, depending on species germination time. Preliminary tests were conducted to determine the appropriate incubation time and temperature for each species (Table 2). Temperature was monitored using data loggers (Watch Dog 100-Temp 2K, Spectrum Technologies, Plainfield, Ill.) set to record temperature every $15 \mathrm{~min}$. After the incubation period, germination percentage was recorded for the vegetables. Seeds were considered to have germinated when radicles reached $2 \mathrm{~mm}$. Radicles of both vegetables and weeds were then separated from the shoot. Then, they were floated in $\mathrm{RO}$ water in a clear plastic tray and scanned using a HP Scanjet 8200 scanner. The images were analyzed for length using WinRHIZO 2003b (Regent Insturments Inc., Ste-Foy, Que. Canada).

Statistical analysis. All data were subjected to analysis of variance to test the differences among treatments and between experiments. When no experiment $\times$ treatment interaction was observed, data from experiment 1 (E1) and E2 were combined. Germination and radicle elongation parameters were analyzed using SAS PROC GLM (Version 8, SAS 2001). Normality was checked using ANOVA. Means were separated using Fisher's protected LSD, and in the event outliers needed to be removed, PDIFF. A p-value of $<0.05$ was used to indicate significance. Regression analyses were performed using TableCurve 2D (Version 4, AISN Software, Inc., 1996).

To allow for comparison among species, data for radicle length were converted to percent of the control for each replicate in each species.

Table 2. Vegetable and weed species used in the bioassays of hairy vetch and cowpea aqueous extracts. Incubation temperatures separated by a slash indicate the $16 / 8 \mathrm{~h}$ fluctuations of the growth chambers.

\begin{tabular}{|c|c|c|c|c|c|}
\hline $\begin{array}{l}\text { Common } \\
\text { name }\end{array}$ & $\begin{array}{l}\text { Scientific } \\
\text { name }\end{array}$ & $\begin{array}{l}\text { Variety/Bayer } \\
\text { code }\end{array}$ & $\begin{array}{l}\text { Incubation } \\
\text { temp } \\
\left({ }^{\circ} \mathrm{C}\right)\end{array}$ & $\begin{array}{l}\text { Incubation } \\
\text { time } \\
\text { (d) }\end{array}$ & $\begin{array}{c}\text { Germination } \\
(\mathbf{0})\end{array}$ \\
\hline \multicolumn{6}{|l|}{ Vegetable crop } \\
\hline Carrot & Daucus carota & Delmar & 21 & 7 & 68.8 \\
\hline Lettuce & Lactuca sativa & Ithaca & 21 & 4 & 96.9 \\
\hline Onion & Allium cepa & Sweet Sandwich & 21 & 5 & 93.2 \\
\hline Pepper & Capsicum annuum & Jalapeno & 21 & 7 & 94.4 \\
\hline \multicolumn{6}{|l|}{ Weed } \\
\hline Barnyardgrass & Echinochloa crus-galli & ECHCG & $30 / 25$ & 7 & 22.5 \\
\hline Common chickweed & Stellaria media & STEME & 21 & 11 & 91.9 \\
\hline Common milkweed & Asclepias syriaca & ASCSY & $30 / 25$ & 4 & 84.4 \\
\hline Redroot pigweed & Amaranthus retroflexus & AMARE & $30 / 25$ & 4 & 85.7 \\
\hline Velvetleaf & Abutilon theophrasti & ABUTH & 21 & 4 & 32.5 \\
\hline Wild carrot & Daucus carota & DAUCA & $30 / 25$ & 7 & 78.2 \\
\hline
\end{tabular}




\begin{tabular}{|c|c|c|c|c|c|c|}
\hline \multirow{2}{*}{$\begin{array}{l}\begin{array}{l}\text { Cover } \\
\text { crop }\end{array} \\
\text { Hairy vetch } \\
\text { Cowpea }\end{array}$} & \multirow[b]{2}{*}{$\begin{array}{c}\text { Area } \\
\text { harvested } \\
\left(\mathrm{m}^{2}\right)\end{array}$} & \multirow{2}{*}{$\begin{array}{c}\text { Total } \\
\text { fresh } \\
\text { biomass } \\
(\mathrm{kg})\end{array}$} & \multirow{2}{*}{$\begin{array}{c}\text { Extract } \\
\text { dry } \\
\text { wt } \\
(\mathrm{g})\end{array}$} & \multicolumn{2}{|c|}{ Ratios } & \multirow{2}{*}{$\begin{array}{c}\text { Extract } \\
\text { field } \\
\text { rates } \\
\left(\mathrm{g} \cdot \mathrm{L}^{-1}\right)\end{array}$} \\
\hline & & & & $\begin{array}{c}\text { Extract/area } \\
\text { harvested } \\
\left(\mathrm{g} \cdot \mathrm{m}^{-2}\right)\end{array}$ & $\begin{array}{c}\text { Extract/fresh } \\
\text { biomass } \\
\left(\mathrm{g} \cdot \mathrm{kg}^{-1}\right)\end{array}$ & \\
\hline
\end{tabular}

${ }^{2}$ The field rate of extract was estimated using the following equation:

$F E R=\left[E(\mathrm{~g})^{*} P\left(\mathrm{~cm}^{3}\right)\right] /\left[A\left(\mathrm{~cm}^{2}\right)^{*} D(\mathrm{~cm})^{*} W(\mathrm{~L})\right]$, where $F E R$ is the estimated extract field equivalent rate, $E$ is the total extract dry weight retrieved in $\mathrm{g}, A$ is the cover crop area harvested, $P$ is the petri dish volume $\left(64 \mathrm{~cm}^{3}\right), D$ is the hypothetical depth of cover crop incorporation in the field $(15 \mathrm{~cm})$, and $W$ is the volume of extract solution added to the petri dish during the bioassay tests in $\mathrm{L}(0.0025 \mathrm{~L})$.

Data on radicle inhibition were fitted to the logistic dose response equation:

$$
E(x)=a+\frac{b}{\left(1+\left(\frac{x}{c}\right)^{d}\right)}
$$

where $R L(x)$ is the radicle length (as a percent of the control) at extract concentration $x, x$ is the extract concentration and $a, b, c$, and $d$, are regression coefficients. A separate model was used to describe the responses when a strong initial radicle stimulation was observed (Norsworthy and Meehan, 2005). The model had the following form:

$E(x)=a * \exp (-0.5 *[[x-b] c])$

where $R L(\mathrm{x})$ is radicle length (as a percent of the control) at extract concentration $x, x$ is extract concentration, $a$ is maximum radicle length (as a percent of the control), $b$ is extract concentration at maximum length, and $c$ is a constant. The regression equations were used to estimate the extract concentration required to cause $25 \%\left(\mathrm{IC}_{25}\right), 50 \%\left(\mathrm{IC}_{50}\right)$, and $75 \%\left(\mathrm{IC}_{75}\right)$ inhibitions of radicle growth.

\section{Results}

Extract production per unit of land area and per unit of biomass. The fresh biomass of cowpea per unit area was higher and yielded about $45 \%$ more extract per kg of fresh biomass than hairy vetch (Table 3 ). Hairy vetch and cowpea produced 44.98 and $107.71 \mathrm{~g} \cdot \mathrm{m}^{-2}$ of extract, respectively. This equated to 22.13 and $32.12 \mathrm{~g}$ of extract per $\mathrm{kg}$ of fresh biomass for hairy vetch and cowpea, respectively.

Effect of cover crop extract on germination. The germination rates of carrot, corn, and onion were significantly impacted by the hairy vetch extracts (Data not shown). With $8.00 \mathrm{~g} \cdot \mathrm{L}^{-1}$ extract, $42.5 \%, 66.3 \%$, and $71.3 \%$ germination were observed for carrot, corn, and onion, respectively. Germination percentages of all other species were not affected by hairy vetch extract.

Carrot and corn germination were significantly affected by the presence of increasing concentrations of cowpea extracts (Data not shown). At $8.00 \mathrm{~g} \cdot \mathrm{L}^{-1}$ of cowpea extract, germination of carrot and corn was $30.0 \%$ and $82.5 \%$, respectively. The germination rates of the other crop species examined were not affected.

Effect of cover crop extract on radicle elongation. The radicle lengths of all vegetable crops and all weed species examined were significantly impacted by increasing concentrations of both hairy vetch and cowpea extracts (Figs. 1 and 2). Generally, the responses were adequately described by the logistic dose response or Eq. [3] (Figs. 1 and 2). The $r^{2}$ values ranged from 0.82 to 0.99 for vegetables and 0.42 to 0.99 for weeds. The only exception was common milkweed, which was not significantly affected by the cowpea aqueous extract and therefore did not fit either equation. Experiment $\times$ treatment interactions were significant for carrot and barnyardgrass each exposed to hairy vetch extract. Therefore, data for those species were analyzed separately for E1 and E2 (Figs. 1 and 2).

Hairy vetch extract. The radicle growth of carrot (E 2) and pepper were stimulated
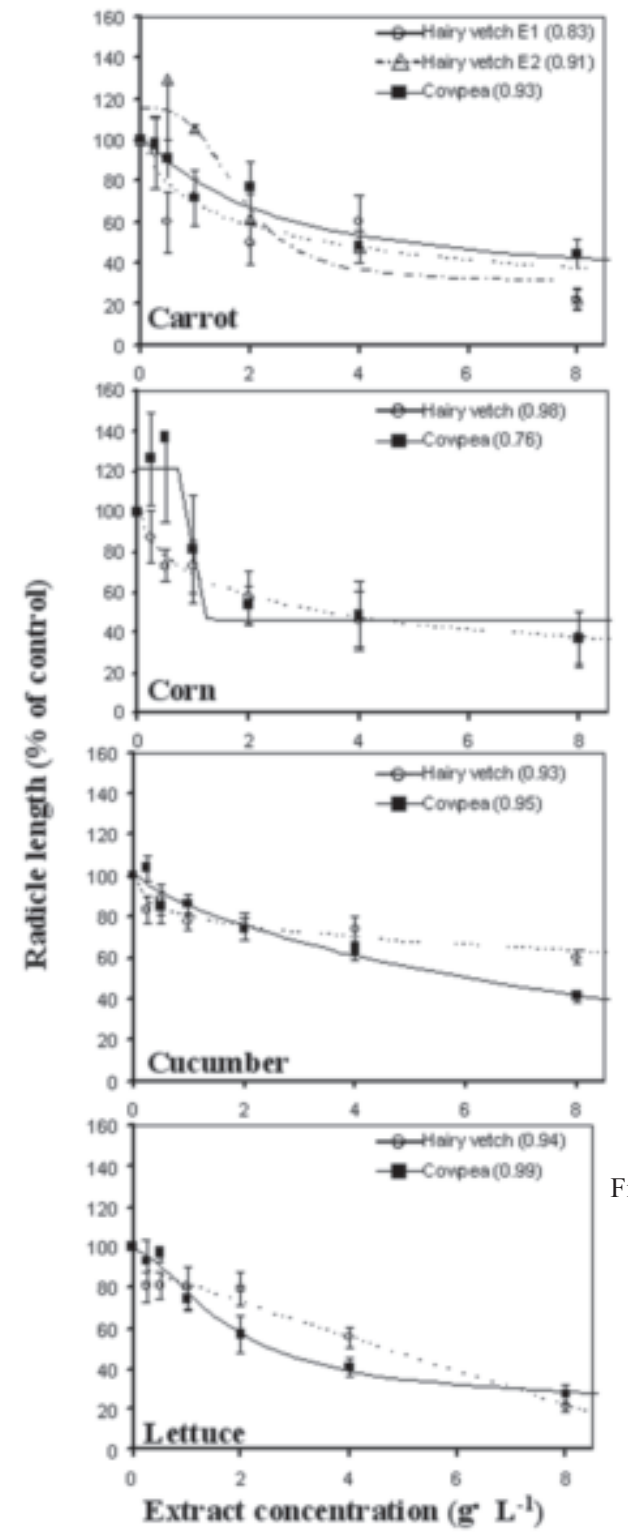

by low concentrations of hairy vetch aqueous extract (Fig. 1). Carrot radicles reached $130.0 \%$ of the control at $0.50 \mathrm{~g} \cdot \mathrm{L}^{-1}$ and pepper was stimulated to $152.8 \%$ at $4.00 \mathrm{~g} \cdot \mathrm{L}^{-1}$. The radicle elongation of the rest of the vegetables was steadily reduced by all concentrations of the hairy vetch aqueous extract. From least to most sensitive (at $8.00 \mathrm{~g} \cdot \mathrm{L}^{-1}$ ) the vegetables have the following order: pepper $<$ cucumber $<$ corn $<$ onion $<$ tomato $<$ carrot $<$ lettuce. Corresponding reductions in growth ranged from 15.5 to $78.9 \%$ of the controls.

Low concentrations of the hairy vetch aqueous extract stimulated the radicle growth
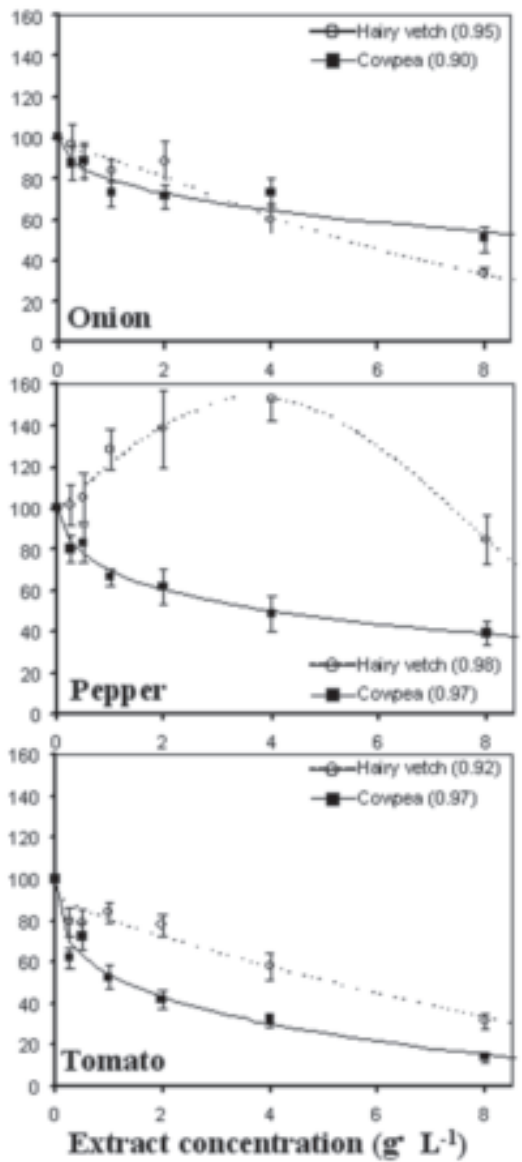

Fig. 1. Radicle growth of several vegetable crops as affected by increasing concentrations of hairy vetch and cowpea aqueous extracts. All data were fitted to the logistic dose response Eq. [2] except pepper exposed to hairy vetch (Eq. [3]). The respective $r^{2}$ values are presented in parentheses in the legend. Data for each crop are combined for Expt. 1 (E1) and Expt. 2 (E2) when there is no treatment $\times$ experiment interaction or presented separately for each experiment when the treatment $\times$ experiment interaction is significant. 

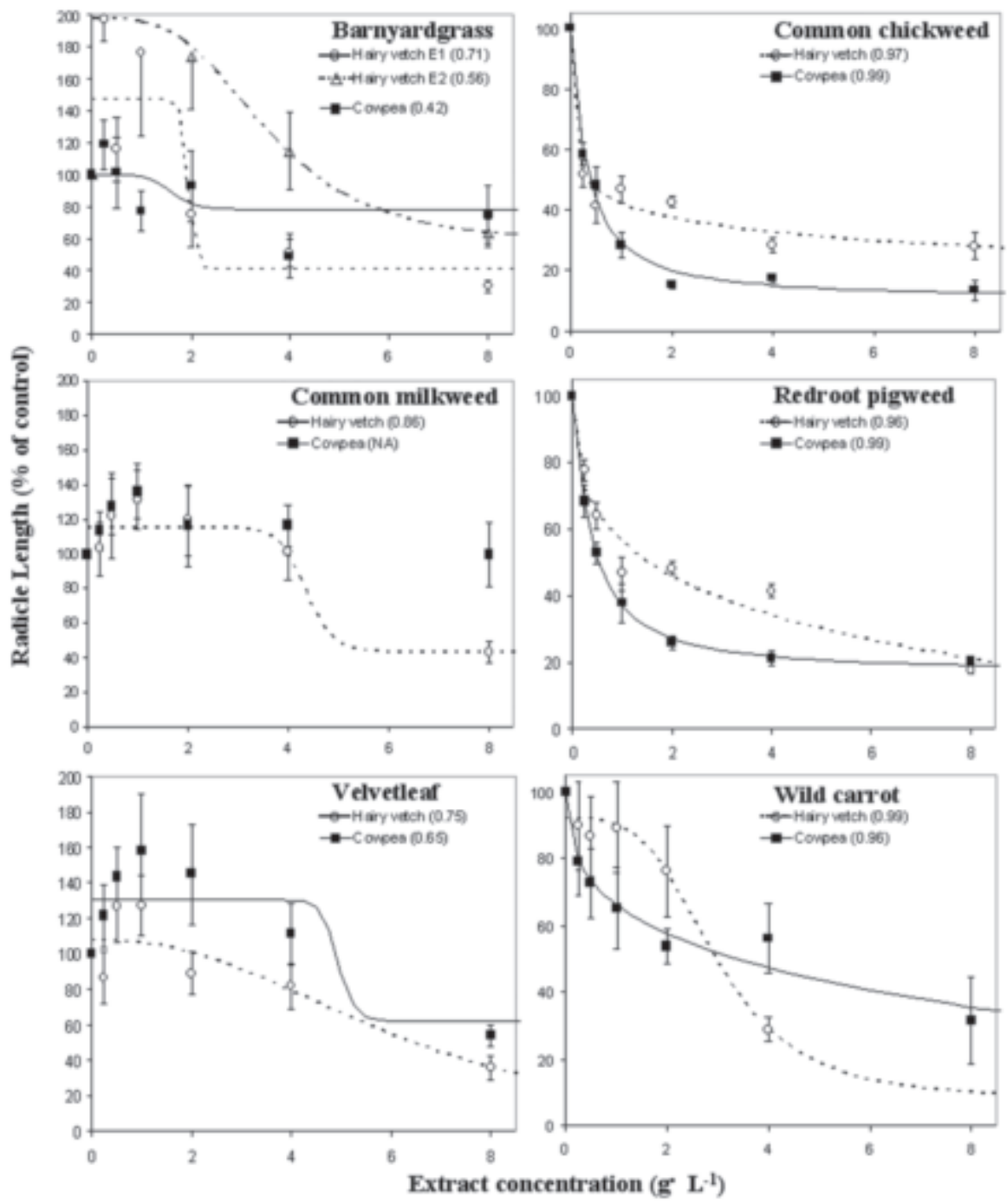

Fig. 2. Radicle growth of several weeds as affected by increasing concentrations of hairy vetch and cowpea aqueous extracts. All data were fitted to the logistic dose response Eq. [2] except common milkweed exposed to cowpea, which did not fit either of our equations. The respective $r^{2}$ values are presented in parentheses in the legend. Data for each weed are combined for Expt. 1 (E1) and Expt. 2 (E2) when there is no treatment $\times$ experiment interaction or presented separately for each experiment when the treatment $\times$ experiment interaction is significant.

of barnyardgrass, common milkweed, and velvetleaf, with maximum lengths of $246.7 \%$ $\left(0.50 \mathrm{~g} \cdot \mathrm{L}^{-1}\right), 131.5 \%\left(1.00 \mathrm{~g} \cdot \mathrm{L}^{-1}\right)$, and $127.0 \%$ $\left(1.00 \mathrm{~g} \cdot \mathrm{L}^{-1}\right)$, respectively (Fig. 2). The other three weeds (common chickweed, redroot pigweed, and wild carrot) experienced a rapid decline in radicle elongation with increasing concentrations of the hairy vetch aqueous extract. From least to most sensitive, the weeds followed: common milkweed $<$ barnyardgrass E1 < velvetleaf $<$ barnyardgrass E2 $<$ common chickweed $<$ redroot pigweed for the $8.00 \mathrm{~g} \cdot \mathrm{L}^{-1}$ concentration. Growth reductions ranged from $36.6 \%$ to $82.3 \%$ of the controls.

Cowpea extract. The presence of cowpea aqueous extracts between 0.25 and $0.50 \mathrm{~g} \cdot \mathrm{L}^{-1}$ stimulated the radicle growth of corn(Fig. 1). A maximum stimulation of $137.2 \%$ of the control was observed at the $0.50 \mathrm{~g} \cdot \mathrm{L}^{-1}$ concentration. All other vegetables tested showed a decline in radicle growth with increasing concentrations of the cowpea aqueous extract. At 8.00 $\mathrm{g} \cdot \mathrm{L}^{-1}$ the crops from least to most sensitive fell in the following order: onion $<$ carrot $<$ cucumber $<$ pepper $<$ corn $<$ lettuce $<$ tomato. The reductions compared to the controls ranged from $49.7 \%$ to $86.4 \%$.

In a trend similar to the hairy vetch aqueous extract, the cowpea extract stimulated the growth of barnyardgrass and velvetleaf radicles at low concentrations, while common chickweed, redroot pigweed, and wild carrot were inhibited by all concentrations. Common milkweed was not affected by the tested concentrations. At $8.00 \mathrm{~g} \cdot \mathrm{L}^{-1}$ the order of weed species from least to most sensitive is: common milkweed $<$ barnyardgrass $<$ velvetleaf $<$ wild carrot $<$ redroot pigweed $<$ common chickweed. Radicle length reductions ranged from 0.4 to $86.6 \%$ of the controls.

Predicted inhibitory concentrations. Radicle elongation of all species examined was significantly impacted by the presence of the two cover crop extracts at varying concentrations (with the exception of common milkweed exposed to cowpea extract). The rates predicted by the regression analyses to cause 25,50 , and $75 \%$ radicle growth reduction provided a better separation among the species tested (Table 4).

$I C_{25}$. Using $\mathrm{IC}_{25}$ values, corn $\left(0.6 \mathrm{~g} \cdot \mathrm{L}^{-1}\right)$ and common chickweed $\left(0.002 \mathrm{~g} \cdot \mathrm{L}^{-1}\right)$ were the most sensitive crop and weed species to hairy vetch, while pepper $\left(8.4 \mathrm{~g} \cdot \mathrm{L}^{-1}\right)$ and velvetleaf $\left(4.35 \mathrm{~g} \cdot \mathrm{L}^{-1}\right)$ were the least susceptible. For cowpea, tomato $\left(0.2 \mathrm{~g} \cdot \mathrm{L}^{-1}\right)$ and common chickweed $\left(0.14 \mathrm{~g} \cdot \mathrm{L}^{-1}\right)$ were the most sensitive and cucumber $\left(2.1 \mathrm{~g} \cdot \mathrm{L}^{-1}\right)$ and velvetleaf (5.18 $\left.\mathrm{g} \cdot \mathrm{L}^{-1}\right)$ were the least affected.

$I C_{50^{\circ}}$ Corn was generally the most sensitive crop to both cover crops $\left(3.3 \mathrm{~g} \cdot \mathrm{L}^{-1}\right.$ for hairy vetch and $1.1 \mathrm{~g} \cdot \mathrm{L}^{-1}$ for cowpea) while cucumber and pepper $\left(>8.0 \mathrm{~g} \cdot \mathrm{L}^{-1}\right)$ were least responsive to hairy vetch and onion $(>8.0$ $\mathrm{g} \cdot \mathrm{L}^{-1}$ ) was least responsive to cowpea. For weed species, common chickweed was most affected by both extract while velvetleaf and barnyardgrass were least affected by hairy vetch and cowpea, respectively.

$I C_{75}$. Finally, for hairy vetch at $\mathrm{IC}_{75}$, lettuce $\left(7.6 \mathrm{~g} \cdot \mathrm{L}^{-1}\right)$ and wild carrot $\left(4.32 \mathrm{~g} \cdot \mathrm{L}^{-1}\right)$ were the most sensitive, while cucumber and barnyardgrass were the least. For cowpea extract, tomato $\left(5.1 \mathrm{~g} \cdot \mathrm{L}^{-1}\right)$ and common chickweed $(1.3$ $\mathrm{g} \cdot \mathrm{L}^{-1}$ ) were the most susceptible and carrot, corn, barnyardgrass and velvetleaf were the least susceptible.

Overall, corn and lettuce were the most susceptible vegetable crops to hairy vetch, while corn and tomato were the most sensitive to cowpea. Common chickweed was the most susceptible weed to cowpea both hairy vetch and. Pepper and onion appear to be the least sensitive vegetables to hairy vetch and cowpea, respectively. Velvetleaf and barnyardgrass appeared to be the most tolerant weed species to aqueous extracts from hairy vetch and cowpea, respectively. The predicted asymptotes reached by carrot, barnyardgrass, and common milkweed for hairy vetch and corn, barnyardgrass, and velvetleaf for cowpea indicate that these species may be more tolerant to higher concentrations of the extracts than the other species examined.

\section{Discussion}

Previously, reports that hairy vetch and cowpea residues and extracts have inhibitory effects on the germination and radicle elongation of both vegetable and weed species have lead to inquiries regarding allelopathy (Hoffman et al., 1993; Hutchinson and McGiffen, 2000; Ngouajio et al., 2003; Ngouajio and Mennan, 2005; Schroeder et al., 1998; Wang et al., 2003; White et al., 1989). This study allowed us to further understand the effects of cowpea and hairy vetch cover crop on the growth of vegetables and weed species under controlled conditions.

Seed germination. In the present study, the germination rates of only three crops were consistently reduced in the presence of the cover crops extracts (carrot and corn for both cowpea and hairy vetch, and onion for hairy vetch). The effect of plant extracts on seed germination has been shown to vary with both 
Table 4. Inhibitory concentrations of hairy vetch and cowpea extracts that reduced vegetable and weed radicle lengths by $25\left(\mathrm{IC}_{25}\right), 50\left(\mathrm{IC}_{50}\right)$, and $75 \%\left(\mathrm{IC}_{75}\right)$. These rates are based on the derived regression analyses for each species.

\begin{tabular}{|c|c|c|c|c|c|c|}
\hline \multirow[b]{2}{*}{ Species $^{y}$} & \multicolumn{3}{|c|}{ Hairy vetch extract $\left(g \cdot \mathrm{L}^{-1}\right)^{z}$} & \multicolumn{3}{|c|}{ Cowpea extract $\left(\mathrm{g} \cdot \mathrm{L}^{-1}\right)$} \\
\hline & $\mathrm{IC}_{25}$ & $\mathrm{IC}_{50}$ & $\mathrm{IC}_{75}$ & $\mathrm{IC}_{25}$ & $\mathrm{IC}_{50}$ & $\mathrm{IC}_{75}$ \\
\hline \multicolumn{7}{|l|}{ Vegetable crop } \\
\hline Carrot & NA & NA & NA & 1.33 & 4.88 & $\infty$ \\
\hline Carrot E1 & 0.55 & 3.88 & $>8.00$ & NA & NA & NA \\
\hline Carrot E2 & 1.75 & 2.62 & $\infty \mathrm{N}$ & $\mathrm{A}$ & NA & NA \\
\hline Corn & 0.64 & 3.34 & $>8.00$ & 1.01 & 1.11 & $\infty$ \\
\hline Cucumber & 2.05 & $>8.00$ & $>8.00$ & 2.06 & 6.08 & $>8.00$ \\
\hline Lettuce & 1.74 & 4.65 & 7.64 & 1.10 & 2.57 & $>8.00$ \\
\hline Onion & 2.56 & 5.37 & $>8.00$ & 1.64 & $>8.00$ & $>8.00$ \\
\hline Pepper & $>8.00$ & $>8.00$ & $>8.00$ & 0.61 & 3.95 & $>8.00$ \\
\hline Tomato & 1.62 & 5.12 & $>8.00$ & 0.15 & 1.28 & 5.08 \\
\hline \multicolumn{7}{|l|}{ Weed } \\
\hline Barnyardgrass & NA & NA & NA & $\infty$ & $\infty$ & $\infty$ \\
\hline Barnyardgrass E1 & 2.00 & 2.12 & $\infty$ & NA & NA & NA \\
\hline Barnyardgrass E2 & 6.12 & $\infty$ & $\infty$ & NA & NA & NA \\
\hline Common chickweed & 0.00 & 0.29 & $>8.00$ & 0.14 & 0.38 & 1.30 \\
\hline Redroot pigweed & 0.19 & 1.55 & 6.58 & 0.19 & 0.54 & 2.34 \\
\hline Velvetleaf & 4.35 & 6.48 & $>8.00$ & 5.18 & $\infty$ & $\infty$ \\
\hline Wild carrot & 2.03 & 2.97 & 4.32 & 0.41 & 3.38 & $>8.00$ \\
\hline
\end{tabular}

z $>8.00$ indicates that the predicted valued was greater than $8.00 \mathrm{~g} \mathrm{~L}^{-1}$ which was the highest extract used in the experiment. NA signifies that the data were either combined or presented by experiment. The $\infty$ signs signify that an asymptote was reached prior to the given reduction.

${ }^{y}$ Data for each crop or weed are combined for Expt. 1 (E1) and Expt. 2 (E2) when there is no treatment $\times$ experiment interaction or presented separately for each experiment when the treatment $\times$ experiment interaction is significant.

the donor species (source of the extract) and the test species (Kadioglu et al., 2005; Kim et al., 2005; Pennacchio et al., 2005). Neutral, stimulatory, and inhibitory effects of plant extracts on seed germination are documented in the literature. Kadioglu et al. (2005) observed 22.5\% inhibition of chick pea seed germination by Matricaria chamomilla extracts and over $90 \%$ stimulation of the same species by Glycyrrhiza glabra, Sorghum halepense, and Reseda lutea extracts. The large variability of seed response to plant extracts has made seed germination a rather inaccurate assessment of the presence of allelochemicals. Lettuce has been proposed as one of the efficient bioassay species but has also been shown to be less responsive to some allelochemicals. More recently, Pennacchio et al. (2005) showed that Arabidopsis thaliana seed germination could be more sensitive to the presence of allelochemicals than the species previously reported in the literature. Lack of germination responses by most species tested in this study to hairy vetch or cowpea extract could simply be due to a low sensitivity of the species to the extracts. If that was proven to be the case, our results would be interesting to growers as this would reduce the risks associated with these cover crops in the field. Although the temperatures used in this work were the optimum for seed germination in the laboratory, these were in most cases different from optimum temperatures for germination in the field. For example, common chickweed germinates best at temperatures significantly lower that those used in this work. Finally, success of a species (both crop and weed) in cropping systems would depend on additional factors, including, radicle growth and seedling establishment.

Radicle elongation. Early radicle growth has been shown to be more responsive to the presence of allelochemicals than seed germination (Leather and Einhellig, 1986). This effect is also species dependant. In this study, a strong stimulatory effect of low rates of hairy vetch extracts was observed on some crops (carrot and pepper) and weeds (barnyardgrass, common milkweed, and velvetleaf). Stimulatory effects of low concentrations of allelochemicals have been reported in many studies (Sinkkonen, 2003). Norsworthy and Meehan (2005) found that at low concentrations, isothiocyanates commonly produced by brassica species stimulate radicle growth of many weed species. Also, barley extracts (Hordeum vulgare) were shown to stimulate durum wheat(Triticum durum) seedling growth (Ben-Hammouda et al., 2001). The stimulatory effect of allelochemicals on crop seedling growth could be exploited in cropping systems to enhance early seedling establishment and to improve competitiveness.

Apart from the species listed above, both hairy vetch and cowpea generally inhibited radicle growth of the weed and crops tested. This is in agreement with observations previously reported by other investigators. Results by Mohler and Teasdale (1993), Ngouajio and Mennan (2005), Teasdale and Daughtry (1993), Teasdale (1996) Teasdale et al. (2005) have shown reduced weed populations in systems with hairy vetch residue. Based on the reduced radicle elongation in cucumber found in response to the hairy vetch extract in this study, the low cucumber stand and growth reported by Ngouajio and Mennan (2005) after a hairy vetch cover crop could be could be associated with leachates from the residue. Moreover, White et al. (1989) reported high sensitivity of corn to hairy vetch residue extracts. In their study, extracts made from dry plant material equivalent to $6.9 \mathrm{~g} \cdot \mathrm{L}^{-1}$, showed a $44 \%$ inhibition of corn germination and $61 \%$ reduction in radicle elongation compared to the control. In the present study, we found $37.5 \%$ reduction in radicle elongation at $8.00 \mathrm{~g} \cdot \mathrm{L}^{-1}$ of hairy vetch aqueous extract. Our study used extracts made from fresh plant material, which may explain the differences between the two reports. Results of the present study strongly suggest that those initial observations could be due to allelochemicals released from the decomposed or hydrolyzed natural products. The reduced radicle lengths of barnyardgrass, common chickweed, and redroot pigweed in response to increasing concentrations of hairy vetch aqueous extract correspond with previous field observations of reduced emergence in the presence of increasing hairy vetch residue rates in the field (Mohler and Teasdale, 1993).

The amount of biomass produced under field conditions was estimated to the equivalent of 7.78 and $18.38 \mathrm{~g} \cdot \mathrm{L}^{-1}$ of extract, for hairy vetch and cowpea, respectively. This assumed that residues were incorporated $15 \mathrm{~cm}$ into the soil (common depth of incorporation of cover crop residue by growers) and that the plant material breaks down simultaneously. Under field conditions, the residues will break down gradually over time. Decomposition rates are dependent on both environmental conditions and biological conditions (Kuo et al., 1997; Weston, 1996; White et al., 1989). Therefore, the concentrations produced by the residues are likely to be lower, perhaps even more so under conditions of high rainfall or frequent irrigation. Under low soil moisture, however, allelochemicals from hairy vetch or cowpea residue could accumulate, reaching concentrations high enough to affect weeds and potentially some crops. While recent studies indicate that cyanamide might be the allelochemical produced by hairy vetch (Kamo et al., 2003), little is known about the potential allelochemical from cowpea

Future studies should examine the relationships between the germination and radicle elongation of vegetable and weed seeds and cover crop aqueous extracts in a greenhouse and field setting. Only then will we have a better view of the potential advantages or dangers when using these two legume cover crops. Finally, to confirm that the observed effects are due to allelochemicals released from the residue, further studies should identify, isolate, and test 
the allelochemical(s) from both of these cover crops. Since most allelochemicals are non polar, extracts obtained with other solvents should also be tested. Understanding the chemistry of allelochemicals in hairy vetch and cowpea extracts will then facilitate the exploration of their potential as natural herbicides.

\section{Literature Cited}

Ben-Hammouda, M., H. Ghorbal, R.J. Kremer, and O. Oueslati. 2001. Allelopathic effects of barley extracts on germination and seedlings growth of bread and durum wheats. Agronomie. 21:65-71.

Bhowmik, P.C. and Inderjit. 2003. Challenges and opportunities in implementing allelopathy for natural weed management. Crop Protection. 22:661-671.

Chase, W.R., M.G. Nair, A.R. Putnam, and S.K. Mishra. 1991. 2,20-Oxo-1,10-azobenzene: Microbial transformation of rye (Secale cereale $\mathrm{L}$.) allelochemical in field soils by Acinetobacter calcoaceticus: III. J. Chem. Ecol. 17:1575-1584.

Chung, I. M. and D. A. Miller. 1995. Natural herbicide potential of alfalfa residue on selected weed species. Agron. J. 87:920-925.

Hoffman, M.L., E.E. Regnier, and J. Cardina. 1993. Weed and corn (Zea mays) responses to a hairy vetch (Vicia villosa) cover crop. Weed Tech. 7:594-599.

Hutchinson, C.M., and M.E. McGiffen, Jr. 2000. Cowpea cover crop mulch for weed control in desert pepper production. HortScience 35:196-198.

Kadioglu I., Y. Yanar, and U. Asav. 2005. Allelopathic effects of weeds extracts against seed germination of some plants. J. Environ. Biol. 26:169-173.
Kamo, T., S. Hiradate, and Y. Fujii. 2003. First isolation of natural cyanamide as a possible allelochemical from hairy vetch. J. Chem. Ecol. 29:275-283.

Kim, Y.O., J.D. Johnson, and E.J. Lee. 2005. Phytotoxic effects and chemical analysis of leaf extracts from three Phytolaccaceae species in South Korea. J. Chem. Ecol. 31: 1175-1186

Kuo. S., U.M. Sainju, and E.J. Jellum. 1997. Winter cover crop effects on soil organic carbon and carbohydrate in soil. Soil Sci. Soc. Amer. J. 61:145-152.

Leather, G.R. and F.A. Einhellig. 1986. Bioassays in the study of allelopathy, p. 133-145. In: A.R. Putnam and C. Tang (eds.). The science of allelopathy. Wiley, New York, N.Y.

Mohler, C.L. and J.R. Teasdale. 1993. Response of weed emergence to rate of Vicia villosa Roth and Secale cereale L. residue. Weed Res. 33:487-499.

Molisch, H. 1937. Der einfluk einer pflanze auf die andere-Allelopathie. Gustave Fischer. Jena, Germany.

Norsworthy, J.K., and J.T. Meehan, IV. 2005. Herbicidal activity of eight isothiocyanates on Texas panicum (Panicum texanum), large crabgrass (Digitaria sanguinalis), and sickle pod (Senna obtusifolia). Weed Sci. 53:515-520.

Ngouajio, M., M.E. McGiffen, Jr., and C.M. Hutchinson. 2003. Effect of cover crop and management system on weed populations in lettuce. Crop Protection 22:57-64.

Ngouajio, M. and H. Mennan. 2005. Weed populations and pickling cucumber (Cucumis sativus) yield under summer and winter cover crop systems. Crop Protection 24:521-526.

Pennacchio, M., L.V. Jefferson, and K. Havens. 2005. Arabidopsis thaliana: A new test species for phytotoxic bioassays. J. Chem. Ecol. 31:1877-1885.
Putnam, A.R. 1988. Allelochemicals from plants as herbicides. Weed Technol. 2:510-518.

Putnam, A.R. 1986. Allelopathy: Can it be managed to benefit horticulture? HortScience 21:411-413.

Schroeder, J.L., B.A. Kahn, and J.Q. Lynd. 1998. Utilization of cowpea crop residues to reduce fertilizer nitrogen inputs with fall broccoli. Crop Sci. 38:741-749.

Sinkkonen, A. 2003. A model describing chemical interference caused by decomposing residues at different densities of growing plants. Plant and Soil 250:315-322.

Teasdale, J.R. 1996. Contribution of cover crops to weed management in sustainable agriculture systems. J. Prod. Agr. 9:475-479.

Teasdale, J.R. and C.S.T. Daughtry. 1993. Weed suppression by live and desiccated hairy vetch (Vicia villosa). Weed Sci. 41:207-212.

Teasdale, J.R. and P. Pillai. 2005. Contribution of ammonium to stimulation of smooth pigweed (Amaranthus hybridus L.) germination by extracts of hairy vetch (Vicia villosa Roth) residue. Weed Biol. Management 5:19-25.

Teasdale, J.R., P. Pillai, and R.T. Collins. 2005. Synergism between cover crop residue and herbicide activity on emergence and early growth of weeds. Weed Sci. 53:521-527.

Wang, K.H., K. McSorley, and R.N. Gallaher. 2003. Host status and amendment effects of cowpea on Meloidogyne incognita in vegetable cropping systems. Nematropica 33:215-224.

Weston, L.A. 1996. Utilization of allelopathy for weed management in agroecosystems. Agron. J. 88:860-866.

Weston, L.A. and S.O. Duke. 2003. Weed and crop allelopathy. Cri. Rev. Plant Sci. 22:367-389.

White, R.H., D. Worsham, and U. Blum. 1989. Allelopathic potential of legume debris and aqueous extracts. Weed Sci. 37:674-679. 